\title{
The associations between air pollutant exposure and neutralizing antibody titers of an inactivated SARS-CoV-2 vaccine
}

\author{
Shaocheng Zhang ${ }^{1}$ (D) Shu Chen ${ }^{1}$. Guangjun Xiao ${ }^{1}$ - Mingcai Zhao ${ }^{1} \cdot \mathrm{Jia} \mathrm{Li}^{1} \cdot$ Wenjuan Dong $^{2} \cdot \mathrm{Juan} \mathrm{Hu}^{1}$. \\ Tianqi Yuan ${ }^{3} \cdot$ Yong Li $^{3}$. Lianghua Liu ${ }^{1}$
}

Received: 29 July 2021 / Accepted: 23 September 2021 / Published online: 1 October 2021

(C) The Author(s), under exclusive licence to Springer-Verlag GmbH Germany, part of Springer Nature 2021

\begin{abstract}
Air pollution is a critical risk factor for the prevalence of COVID-19. However, few studies have focused on whether air pollution affects the efficacy of the SARS-CoV-2 vaccine. To better guide the knowledge surrounding this vaccination, we conducted a cross-section study to identify the relationships between air pollutant exposure and plasma neutralizing antibody (NAb) titers of an inactivated SARS-CoV-2 vaccine (Vero cell, CoronaVac, SINOV $\Lambda$ C, China). We recruited 239 healthcare workers aged 2150 years who worked at Suining Central Hospital. Of these, 207 were included in this study, depending on vaccination date. The data regarding air pollutants were collected to calculate individual daily exposure dose (DED). The geometric mean of all six pollutant DEDs was applied to estimate the combined toxic effects $\left(\mathrm{DED}_{\text {complex }}\right)$. Then, the participants were divided into two groups based on the mean value of $\mathrm{DED}_{\text {complex. }}$. The median plasma NAb titer was $12.81 \mathrm{AU} / \mathrm{mL}$, with $85.99 \%$ vaccine efficacy in healthcare workers against SARS-CoV-2. In exposure group, observations included lower plasma NAb titers (median: 11.13 $\mathrm{AU} / \mathrm{mL}$ vs. $14.56 \mathrm{AU} / \mathrm{mL}$ ), more peripheral counts of white blood cells and monocytes (mean: $6.71 \times 10^{9} / \mathrm{L}$ vs. $6.29 \times 10^{9} / \mathrm{L}$ and $0.49 \times 10^{9} / \mathrm{L}$ vs. $0.40 \times 10^{9} / \mathrm{L}$, respectively), and a higher peripheral monocyte ratio $(7.38 \%$ vs. $6.50 \%)$ as compared to the reference group. In addition, elevated air pollutant DEDs were associated with decreased plasma NAb titers. To our knowledge, this study is the first to report the relationship between air pollutant exposure and plasma NAb titers of the SARS-CoV-2 vaccine. This suggests that long-term exposure to air pollutants may inhibit plasma NAb expression by inducing chronic inflammation. Therefore, to achieve early herd immunity and hopefully curb the COVID-19 epidemic, vaccinations should be administered promptly to those eligible, and environmental factors should be considered as well.
\end{abstract}

Keywords Air pollutants $\cdot$ Combined toxic effects $\cdot$ Neutralizing antibody titer $\cdot$ Inactivated SARS-CoV-2 vaccine $\cdot$ Chronic inflammation $\cdot$ Healthcare workers

Shaocheng Zhang, Shu Chen and Guangjun Xiao contributed equally as co-first authors.

Responsible Editor: Lotfi Aleya

Shaocheng Zhang

Zinssercheung@163.com

1 Department of Clinical Laboratory Medicine, Suining Central Hospital, 127 Deshengxi Rd., Suining 629000, Sichuan, People's Republic of China

2 Department of Public Health Administration and Health Education, Suining Central Hospital, Suining 629000, Sichuan, People's Republic of China

3 Maccura Biotechnology Co. Ltd., Chengdu 611731, Sichuan, People's Republic of China

\section{Abbreviations}

DED Daily exposure dose

$\mathrm{NAb}$ Neutralizing antibody

\section{Introduction}

Coronavirus disease 2019 (COVID-19), which is caused by severe acute respiratory syndrome coronavirus 2 (SARSCoV-2), has spread rapidly in more than 230 countries and regions and now poses an unprecedented threat to public health and socio-economic security (Barouki et al. 2021; Chen et al. 2021; He et al. 2021; Zhang et al. 2021a). SARS-CoV-2 might be able to survive in wastewater and hospital ward air and may persist on surfaces such as masks, handles, cupboards, switches, and fuel gun nozzle for a long 
period, which presents a big threat of infection for those in a variety of different occupations (Dargahi et al. 2021a; Dargahi et al. 2021b; Karami et al. 2021a; Karami et al. 2021b; Sarailoo et al. 2021; Vosoughi et al. 2021). The World Health Organization (WHO) reported that there were about 226.23 million confirmed cases of COVID-19 and more than 4.65 million deaths worldwide as of September 16, 2021 (WHO. 2021). Vaccination is considered an essential step to obtain herd immunity against COVID-19. At this point, about 5.63 billion vaccine doses have been administered around the world (Amanat and Krammer 2020; He et al. 2021; Hodgson et al. 2021; WHO. 2021). Mounting research has reported that the efficacies of different SARS-CoV-2 vaccines ranged from 62.1 to $95.0 \%$ (Al Kaabi et al. 2021; Baden et al. 2021; Logunov et al. 2021; Polack et al. 2020; Sadoff et al. 2021; Voysey et al. 2021). However, few studies have focused on whether air pollution affects the efficacy of the SARS-CoV-2 vaccine.

Air pollutants are the critical risk factors for respiratory infection and play a crucial role in the prevalence of COVID-19 (Fareed et al. 2020; Sarwar et al. 2021; Shakoor et al. 2020; Zhang et al. 2019a; Zhang et al. 2019b; Zhang et al. 2021c). Systematic retrospective analyses indicated that SARS-CoV-2 could adhere to air particulate matter (PM), while $\mathrm{PM}$ and $\mathrm{NO}_{2}$ might make the important contributions to the prevalence and lethality of COVID-19 through upregulation of angiotensin-converting enzyme 2 expression in respiratory cells (Copat et al. 2020; Paital and Agrawal 2020; Srivastava 2021). Air pollutants may inhibit viral clearance and promote viral spread by preventing macrophage uptake and elevating epithelial permeability (Woodby et al. 2021). Epidemiological studies have reported that the short-term toxic effects of air pollutants were significantly associated with COVID-19 cases, showing that per $10 \mu \mathrm{g} / \mathrm{m}^{3}$ enhancement of $\mathrm{PM}_{2.5}, \mathrm{PM}_{10}, \mathrm{O}_{3}$, and $\mathrm{NO}_{2}$, the daily confirmed cases of COVID-19 will increase by $2.24 \%, 1.76 \%, 4.76 \%$, and $6.94 \%$, respectively (Zhang et al. 2021c; Zhu et al. 2020). In the event of long-term exposure, each $1 \mathrm{~m}^{3}$ increase of $\mathrm{PM}_{2.5}$ could increase the confirmed cases of COVID-19 by $12 \%$ (Travaglio et al. 2021). In terms of mortality, the long-term exposure effects of air pollutants have been highlighted previously, and the results suggested that a $1 \mu \mathrm{g} / \mathrm{m}^{3}$ enhancement of $\mathrm{PM}_{2.5}$ was associated with $1.4 \%$ (England), $0.76 \%$ (Mexico), and $8 \%$ (USA) increase in COVID-19 mortality, while a $\mathrm{NO}_{2}$ increase by $1 \mu \mathrm{g} / \mathrm{m}^{3}$ could increase COVID-19 mortality by $0.5 \%$ in England (Konstantinoudis et al. 2021; Lopez-Feldman et al. 2021; Wu et al. 2020). In total, air pollution may accelerate the risk of COVID-19 transmission and lethality (Fareed et al. 2020; Shahzad et al. 2020; Shahzad et al. 2021). Although the role of air pollutants in COVID19 prevalence has previously been emphasized, the relationships between air pollutants and neutralizing antibody (NAb) titers of the SARS-CoV-2 vaccine remain unclear.
Environmental pollution poses a greater risk of dangerous COVID-19 re-bursting than SARS-CoV-2 spike (Paital and Das 2021). In addition, our previous studies have determined that children who lived in an e-waste area with serious air pollution had the lower vaccine antibody titers against diphtheria, hepatitis B, Japanese encephalitis, measles, mumps, pertussis, polio, rubella, and tetanus than children who lived in another reference area (Cong et al. 2018; Lin et al. 2017; Lin et al. 2016; Xu et al. 2015; Zhang et al. 2019a; Zheng et al. 2016). The current study aims to investigate the effects of air pollutants on SARS-CoV-2 vaccine efficacy, and we hypothesize that long-term exposure to air pollutants will inhibit vaccine NAb titers against SARS-CoV-2. To prove this hypothesis, we (i) calculated the daily exposure dose (DED) of air pollutants $\left(\mathrm{PM}_{2.5}, \mathrm{PM}_{10}, \mathrm{SO}_{2}, \mathrm{NO}_{2}, \mathrm{O}_{3}\right.$, and $\left.\mathrm{CO}\right)$ and their combined effects, (ii) assessed chronic inflammatory levels and plasma NAb titers after SARS-CoV-2 vaccination, and (iii) estimated the relationships between air pollutants and $\mathrm{NAb}$ titers in healthcare workers.

\section{Materials and methods}

\section{Study population}

A total of 239 healthcare workers from the ages of 21-50 years old at Suining Central Hospital were recruited randomly in this cross-sectional study during the period of April 22-23, 2021. To rule out the impact of different vaccination dates, the present study ultimately included 207 healthcare workers who received the first and second doses of inactivated SARS-Cov2 vaccine (Vero cell, CoronaVac, SINOV $\Lambda$ C, China) on February 8, 2021, and March 10, 2021, respectively. Until biological sampling, all participants were free of any known medical condition, and signed an informed consent. To collect the basic information on lifestyle, living environment, educational status, and household monthly income, a questionnaire was complete by all individuals through the Sojump network platform. This study was approved by the Medical Research Ethics Committee of Suining Central Hospital, China (LLSNCH20210012).

\section{Sampling and laboratory measurements}

All operations were performed according to the mustard of International Standardization Organization (ISO) 15189 quality and management. The following participant metrics were collected by trained nurses: general physical information, including height and weight, and fasting cubital vein blood sampling. EDTA anticoagulant $(2 \mathrm{~mL})$ blood was applied to analyze the peripheral inflammatory cells and heparin sodium anticoagulant $(5 \mathrm{~mL})$ blood was used to separate plasma by centrifugation at $3500 \mathrm{rpm}$ for $5 \mathrm{~min}$ at room temperature. 
After this, the remainder of the blood and plasma was aliquoted and stored at $-80^{\circ} \mathrm{C}$.

Peripheral white blood cell (WBC) counts, monocyte counts, and the ratios of monocytes were tested by an automatic hematology analyzer (Sysmex XN-9000, Japan) within $1 \mathrm{~h}$ of sampling. Plasma was applied to measure NAb titers and assess health status. This included aspartate aminotransferase (AST), alanine aminotransferase (ALT), total protein, albumin, total bilirubinuric, direct bilirubinuric, total cholesterol, triglycerides, high-density lipoprotein-cholesterol (HDL-C), low-density lipoprotein-cholesterol (LDL-C), apolipoprotein $\mathrm{A} 1$, apolipoprotein $\mathrm{B}$, urea, creatinine, and cystatin C. All health biomarkers were analyzed by an automatic biochemical analyzer (Hitachi LST 7600, Japan), and $\mathrm{NAb}$ titers were tested by an automatic chemiluminescence immunoassay analyzer (Maccura i 3000, China).

\section{Exposure assessment}

Four stations in Suining $\left(85.04 \mathrm{~km}^{2}\right.$ area, http://stjj.suining. gov.cn/tjnj) monitor air pollutant concentrations $\left(\mathrm{PM}_{2.5}\right.$, $\mathrm{PM}_{10}, \mathrm{SO}_{2}, \mathrm{NO}_{2}, \mathrm{O}_{3}$, and $\mathrm{CO}$ ), ensuring the individual activity radius of all participants less than $40 \mathrm{~km}$ from the nearest station, which is the threshold of monitoring station air pollutant data for assessing individual exposure (Bowe et al. 2017; Wang et al. 2020). Air pollutant data was released through the national real-time urban air quality platform (http://106.37.208.233:20035/), and collected to calculate individual air pollutant DED using a modified formula: $\mathrm{DED}_{\mathrm{i}}=$ $C_{\mathrm{i}} \times$ inhalation rate (IR) $\times$ individual weight $/$ reference weight (Wang et al. 2020; Zheng et al. 2016). In this formula, $C_{\mathrm{i}}$ is the median concentration of pollutant $\mathrm{i}\left(\mathrm{PM}_{2.5}, \mathrm{PM}_{10}, \mathrm{SO}_{2}, \mathrm{NO}_{2}\right.$, $\mathrm{O}_{3}$, and $\mathrm{CO}$ ). IR was estimated by parameters of the adult, and the reference weights for adult males and females were $60 \mathrm{~kg}$ and $51 \mathrm{~kg}$, respectively (Table S1) (Zheng et al. 2016). The assessment method of individual outdoor exposure time was described in our previous study in detail (Zhang et al. 2019a). In addition, we also estimated the DED of combined toxic effects $\left(\mathrm{DED}_{\text {complex }}\right)$ using the geometric mean of all six pollutant DEDs. Then, we divided all participants into two groups based on $\mathrm{DED}_{\text {complex }}$ mean. The reference group was defined as $\mathrm{DED}_{\text {complex }} \leq 0.8 \mathrm{mg} /$ day, and the exposure group was defined as $\mathrm{DED}_{\text {complex }}>0.8 \mathrm{mg} /$ day.

\section{Statistical analysis}

Mean \pm standard deviation (SD) or median interquartile range (IQR) was used to depict data depending on the distribution characteristics, which were estimated by the KolmogorovSmirnov test. Logarithmic transformation was conducted to approximate and normalize the data distribution in plasma $\mathrm{NAb}$ titers. As expected, group differences were determined by the independent-samplet-test or the Mann-Whitney $U$ test.
The seasonal distribution characteristics of air pollutants were analyzed by the Kruskal-Wallis test. The Spearman rank correlation test was performed to identify associated confounders of air pollutant DEDs. In addition, multivariable-adjusted linear regression models were applied to assess the dose-effect relationships between air pollutant DEDs and plasma NAb titers. Covariates included gender, age, height, daily cigarette smoking, daily alcohol drinking, window opening frequency, distance between residence and road, educational status, and household monthly income (Cong et al. 2018; Zhang et al. 2019a). SPSS (version 22.0; IBM, USA) and GraphPad Prism (version 8.0; GraphPad, CA) were applied to analyze data and edit figures, respectively. $P<0.05$ was statistically significant and was defined in a two-tailed test.

\section{Results and discussion}

\section{General characteristics of the study population}

There were 207 healthcare workers recruited in this crosssectional study (Table S2). The gender ratio (male/female) was $69 / 138$, and the median age was 31 years. The median of height and weight was $1.62 \mathrm{~m}$ and $56 \mathrm{~kg}$, respectively. Most participants had no history of cigarette smoking $(86.96 \%)$ or alcohol drinking $(70.53 \%)$, spent more time $(>2 \mathrm{~h})$ outdoor per day $(43.96 \%)$, lived far away $(>100 \mathrm{~m})$ from the road $(47.83 \%)$, or had a relatively lower income (below 10,000 yuan per month, $48.79 \%$ ). In terms of health status, the median concentrations of AST, ALT, total bilirubinuric, direct bilirubinuric, triglycerides, and creatinine were found to be $21 \mathrm{U} / \mathrm{L}, 14 \mathrm{U} / \mathrm{L}, 7.7 \mu \mathrm{mol} / \mathrm{L}, 2.2 \mu \mathrm{mol} / \mathrm{L}, 1.32 \mathrm{mmol} / \mathrm{L}$, and $60 \mu \mathrm{mol} / \mathrm{L}$, respectively. The mean concentrations of total protein, albumin, total cholesterol, HDL-C, LDL-C, apolipoprotein $\mathrm{A} 1$, apolipoprotein $\mathrm{B}$, urea, and cystatin $\mathrm{C}$ were found to be $79.38 \mathrm{~g} / \mathrm{L}, 48.47 \mathrm{~g} / \mathrm{L}, 4.67 \mathrm{mmol} / \mathrm{L}, 1.23 \mathrm{mmol} / \mathrm{L}, 2.5$ $\mathrm{mmol} / \mathrm{L}, 1.56 \mathrm{~g} / \mathrm{L}, 0.78 \mathrm{~g} / \mathrm{L}, 5.36 \mathrm{mmol} / \mathrm{L}$, and $0.76 \mathrm{mg} / \mathrm{L}$, respectively.

\section{Air pollutant DEDs and the associated factors}

The annual mean concentrations of air pollutants were found to be $29.77 \mu \mathrm{g} / \mathrm{m}^{3}\left(\mathrm{PM}_{2.5}\right), 50.93 \mu \mathrm{g} / \mathrm{m}^{3}\left(\mathrm{PM}_{10}\right), 8.62 \mu \mathrm{g} / \mathrm{m}^{3}$ $\left(\mathrm{SO}_{2}\right), 20.50 \mu \mathrm{g} / \mathrm{m}^{3}\left(\mathrm{NO}_{2}\right), 61.79 \mu \mathrm{g} / \mathrm{m}^{3}\left(\mathrm{O}_{3}\right)$, and $602.98 \mu \mathrm{g} /$ $\mathrm{m}^{3}$ (CO) (Figure 1 and Table S3). These results suggested that the air quality in Suining is better than in other cities, including Chengdu, Chongqing, Mianyang, and Fuling in the Sichuan Basin (Huang et al. 2020; Qiao et al. 2019; Wang et al. 2018; Wang et al. 2020; Zhang et al. 2021b). This difference might be attributed to the relatively low industrial status and small traffic flow in Suining. In addition, the concentration of air pollutants in Suining showed a seasonal difference, indicating that air pollution was severe in winter and low in summer (all 
Fig. 1 Distribution characteristics of air pollutant concentrations and daily exposure doses

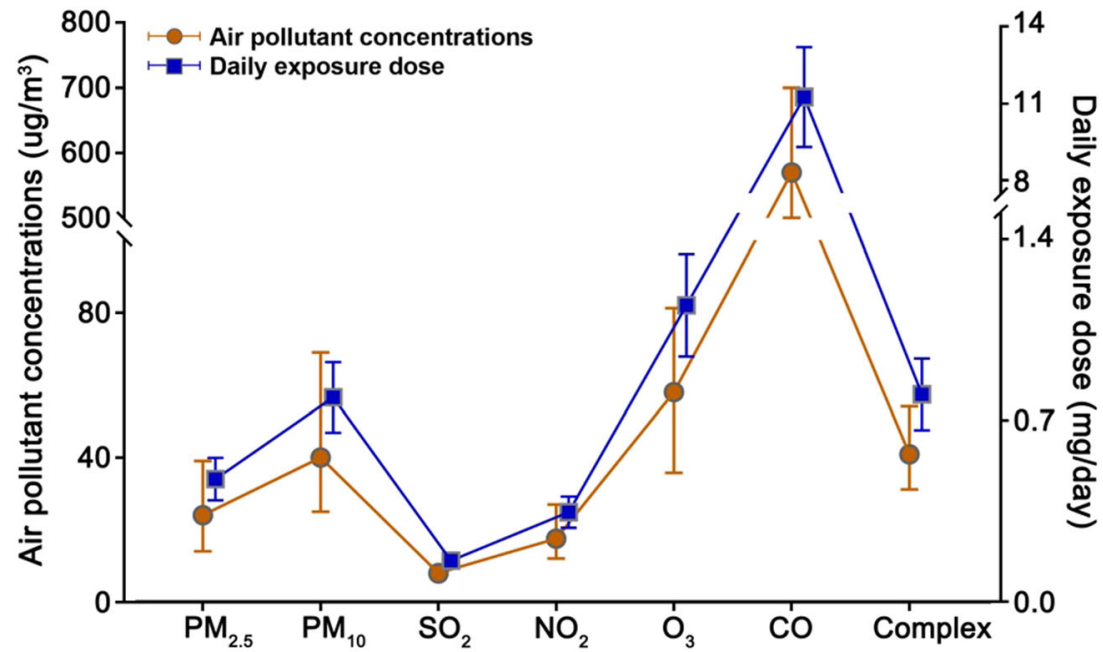

$P<0.01)$ (Table S3). The seasonal characteristics were consistent with previous studies (Wang et al. 2018; Wang et al. 2020; Zhang et al. 2021b).

The mean levels of air pollutant DEDs were found to be $0.47 \mathrm{mg} /$ day (DED $\left.{ }_{\mathrm{PM} 2.5}\right), 0.79 \mathrm{mg} /$ day $\left(\mathrm{DED}_{\mathrm{PM} 10}\right), 0.16 \mathrm{mg} /$ day $\left(\mathrm{DED}_{\mathrm{SO} 2}\right), 0.35 \mathrm{mg} /$ day $\left(\mathrm{DED}_{\mathrm{NO} 2}\right), 1.14 \mathrm{mg} / \mathrm{day}$ $\left(\mathrm{DED}_{\mathrm{O} 3}\right), 11.25 \mathrm{mg} / \mathrm{day}\left(\mathrm{DED}_{\mathrm{CO}}\right)$, and $0.80 \mathrm{mg} / \mathrm{day}$ $\left(\mathrm{DED}_{\text {Complex }}\right.$ ) (Figure 1). Spearman rank correlation test was performed to identify whether there were confounders associated with air pollutant DEDs and indicated that air pollutant DEDs were correlated with height and unhealthy lifestyle (including cigarette smoking and alcohol consumption), whereas not associated with living environment, educational status, and household monthly income. For example, DED ${ }_{\mathrm{PM} 2.5}$ was found to be positively associated with height, daily cigarette smoking, and daily alcohol consumption $\left(r_{\mathrm{s}}=0.652, r_{\mathrm{s}}=\right.$ 0.264 , and $r_{\mathrm{s}}=0.366$, respectively, all $P<0.01$ ) (Table S4). Our previous studies determined that apart from lifestyle, the variables of living environment, parental educational status, and family socio-economic status were associated with pollution exposure levels in children (Lu et al. 2018; Zhang et al. 2019a). This difference may result from the idea that there is a higher environmental susceptibility in children than adults (Wild and Kleinjans 2003; Zhang et al. 2014). Collectively, unhealthy lifestyles could increase the risk of exposure to air pollutants, which had been highlighted.

\section{Peripheral inflammatory status}

Peripheral leukocytes play a crucial immune-regulatory role in systemic inflammation, and monocytes are chronic inflammatory biomarkers (Chabot-Richards and George 2014; So et al. 2021; Zhang et al. 2019a). Air pollution exposure could induce immunodysregulation and the systemic inflammatory response that involves monocytes and neutrophils (Calderon-Garciduenas et al. 2009; Xu et al. 2013). Group difference analysis showed in the exposure group, the peripheral counts of WBCs and monocytes were higher than in the reference group, accompanied by a higher ratio of monocytes in the exposure group (mean: $6.71 \times 10^{9} / \mathrm{L}$ vs. $6.29 \times 10^{9} / \mathrm{L}$, $0.49 \times 10^{9} / \mathrm{L}$ vs. $0.40 \times 10^{9} / \mathrm{L}$, and $7.38 \%$ vs. $6.50 \%$, respectively, all $P<0.05$ ) (Figure 2). Although there was no significant correlation between air pollution and peripheral leukocyte counts in disease models, mounting literature has suggested that air pollutant exposure $\left(\mathrm{PM}_{2.5}, \mathrm{PM}_{10}, \mathrm{NO}_{2}\right.$, black carbon, and sulfate) could increase peripheral counts of WBCs, monocytes, and neutrophils in healthy human (Dabass et al. 2018; Rich et al. 2012; Verheyen et al. 2021; Zhang et al. 2019a). This cross-sectional study was conducted in healthcare workers and suggested that the increased peripheral counts of WBCs, monocytes, and monocyte ratio in the exposure group was consistent with previous studies in healthy population. In total, this study indicated that longterm air pollutant exposure induced chronic inflammation in healthcare workers.

\section{Plasma NAb titers and the relationships with air pollutant DEDs}

The median plasma NAb titer was $12.81 \mathrm{AU} / \mathrm{mL}$, and $85.99 \%$ ( $n=178$ ) of the participants exceeded or equaled $6 \mathrm{AU} / \mathrm{mL}$, which was the cutoff value provided by the manufacturer. This suggests an $85.99 \%$ vaccine efficacy in healthcare workers against SARS-CoV-2. In addition, plasma NAb titers of the participants were lower in the exposed group than in the reference group (median: $11.13 \mathrm{AU} / \mathrm{mL}$ vs. $14.56 \mathrm{AU} / \mathrm{mL}, P$ $<0.05$ ) (Figure 3). Recently, a phase 3 clinical trial reported that inactivated whole-virion SARS-CoV-2 vaccine (CoronaVac, SINOV $\Lambda$ C, China) has shown $83.5 \%$ efficacy in Turkey (Tanriover et al. 2021). Other studies have also indicated that the efficacies of different SARS-CoV-2 vaccines ranged from 62.1 to $95.0 \%$ (Al Kaabi et al. 2021; 
Fig. 2 Group differences of peripheral cell counts and monocyte ratio. Data are analyzed by independent-samplet-test, ${ }^{*} P$ $<0.05,{ }^{* * * *} P<0.001$

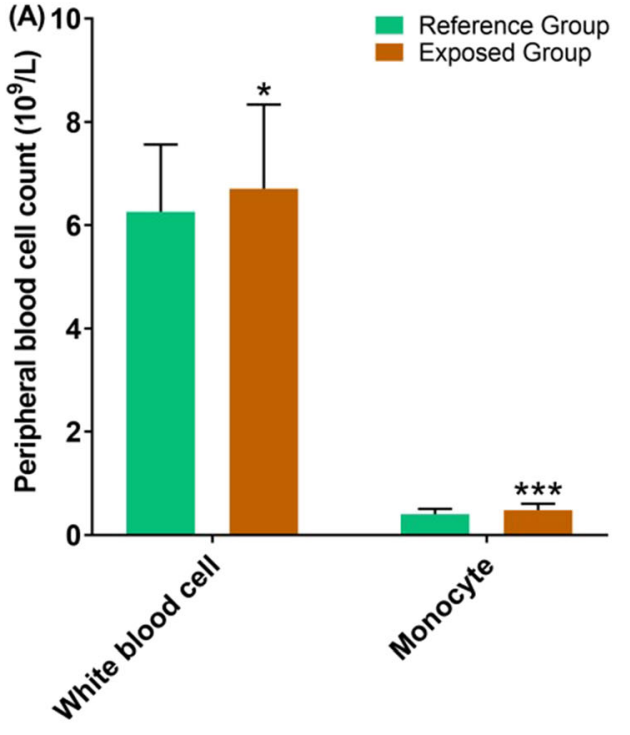

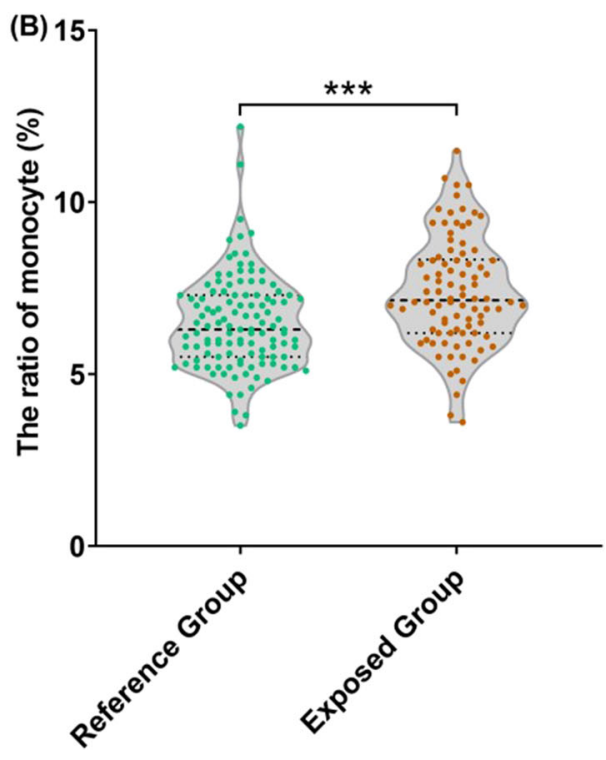

Baden et al. 2021; Logunov et al. 2021; Polack et al. 2020; Sadoff et al. 2021; Voysey et al. 2021). Although this study was performed in a specific group of healthcare workers, which differs from the vaccine types and race of participants in previous studies, the high efficacy of the inactivated SARSCov-2 vaccine (Vero cell, CoronaVac, SINOV $\Lambda$ C, China) is emphasized in the present study.

Our previous studies were performed in an e-waste recycling area where the air pollution was severe have suggested that environmental pollutant exposure could suppress vaccine antibody titers against diphtheria, hepatitis B, Japanese encephalitis, measles, mumps, pertussis, polio, rubella, and tetanus in children (Cong et al. 2018; Lin et al.

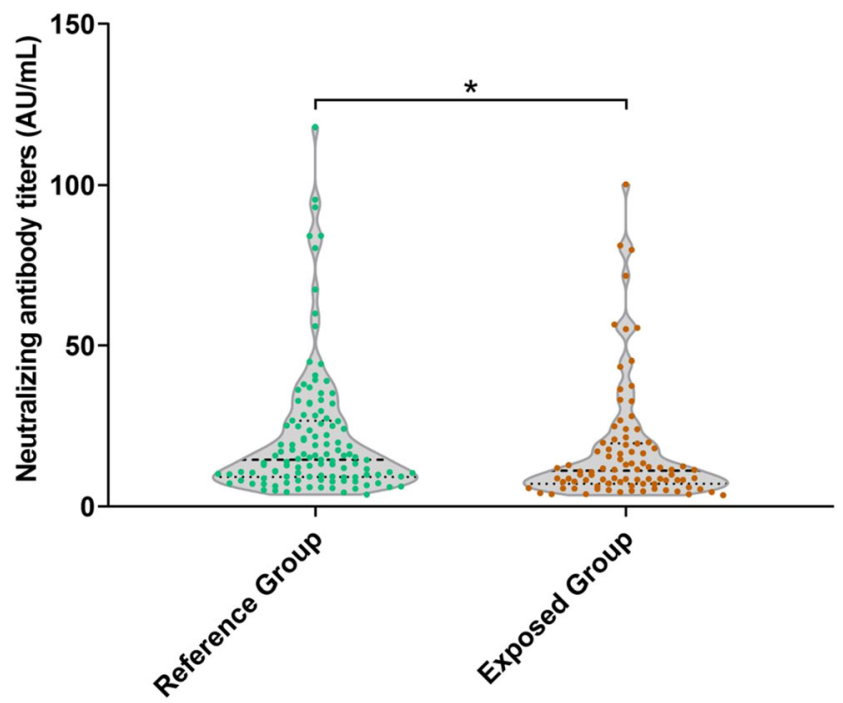

Fig. 3 Distribution characteristic of plasma NAb titers. NAb, neutralizing antibody; data are analyzed by the Mann-Whitney $U$ test; ${ }^{*} P<0.05$
2017; Lin et al. 2016; Xu et al. 2015; Zhang et al. 2019a; Zheng et al. 2016). In addition, Paital and Das (2021) indicated that environmental pollution poses a greater danger of COVID-19 re-bursting than the SARS-CoV-2 spike. Therefore, we determined the relationships between air pollutant DEDs and plasma NAb titers by using the multivariable-adjusted linear regression model (Figure 4). Covariates were adjusted and included gender, age, height, daily cigarette smoking, daily alcohol consumption, window opening frequency, distance between residence and road, educational status, and monthly household income. The regression analyses indicated that air pollutant DEDs were significantly and negatively associated with plasma NAb titers [B (95\% CI): $-0.809(-1.600,-0.019)$ for $\mathrm{PM}_{2.5},-0.486$ $(-0.960,-0.011)$ for $\mathrm{PM}_{10},-2.427(-4.800,-0.055)$ for $\mathrm{SO}_{2},-1.139(-2.211,-0.068)$ for $\mathrm{NO}_{2},-0.335(-0.662$, $-0.008)$ for $\mathrm{O}_{3},-0.034(-0.067,-0.001)$ for $\mathrm{CO}$, and $-0.485(-0.954,-0016)$ for combined toxic effects, all $P<$ 0.05], which suggested that with each $1 \mathrm{mg}$ /day DED increment of $\mathrm{PM}_{2.5}, \mathrm{PM}_{10}, \mathrm{SO}_{2}, \mathrm{NO}_{2}, \mathrm{O}_{3}, \mathrm{CO}$, and combined toxic effects, the logarithmic transformation of plasma NAb titers will decrease by 0.809 units, 0.486 units, 2.427 units, 1.139 units, 0.335 units, 0.034 units, and 0.485 units, respectively. Indeed, the results of the present study were consistent with those of previous studies, which highlighted that long-term exposure to environmental pollutants could inhibit the expression of the vaccine antibody in humans (Lin et al. 2017; Lin et al. 2016; Xu et al. 2015). Previous literature has indicated that environmental pollution posed a dangerous risk of COVID-19 epidemic re-bursting, preventive measures, such as mask-wearing and cleaning surfaces with $70 \%$ ethanol spray, are essential to limit infection (Paital 2020; Paital and Das 2021). Of course, to achieve early herd immunity and 
Fig. 4 Associations between air pollutant DEDs and plasma NAb titers. B, unstandardized coefficient; $\mathrm{CI}$, confidence interval; NAb, neutralizing antibody; DED, daily exposure dose; adjusted for gender, age, height, daily cigarette smoking, daily alcohol consumption, window opening frequency, distance between residence and road, educational status, and monthly household income; ${ }^{*} P<0.05$

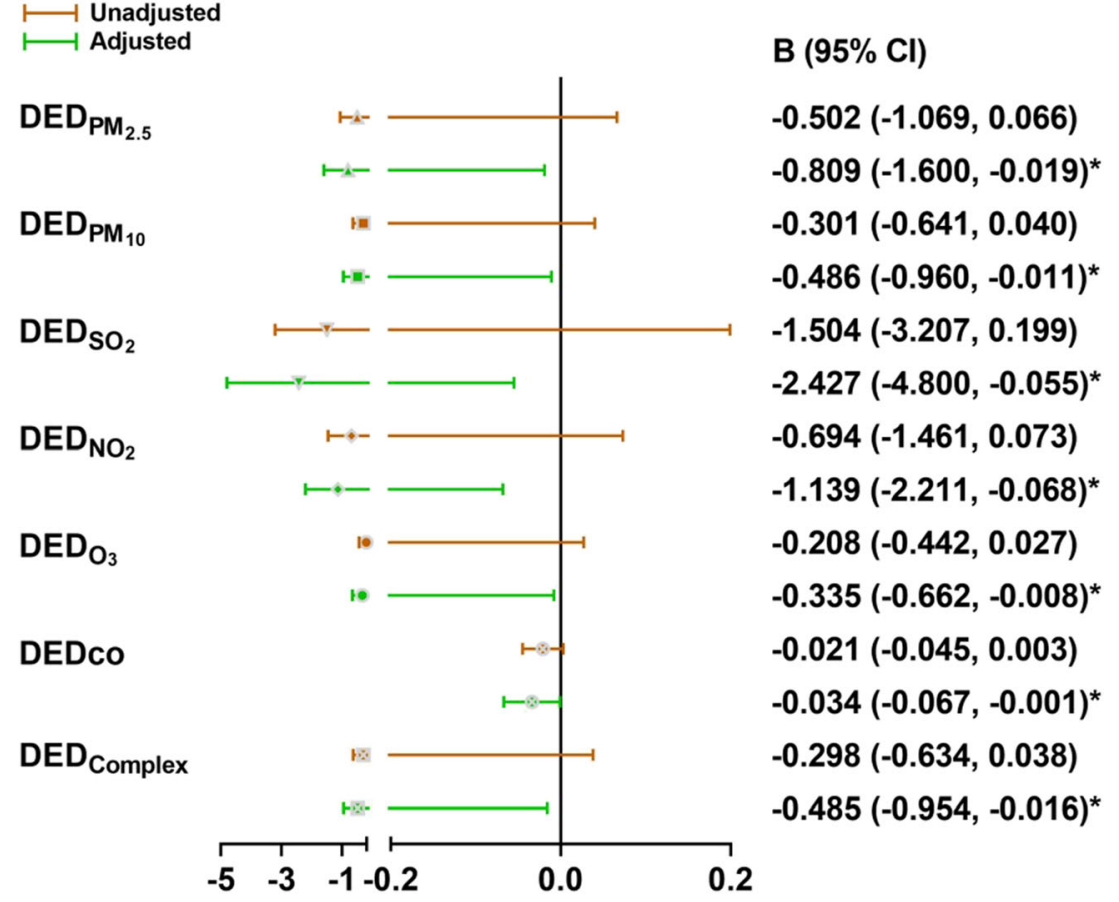

stop the COVID-19 epidemic, vaccinations should be administered promptly, and environmental factors should be considered as well.

Several limitations of this cross-sectional study need to be noted. The sample size was small, and the only participants recruited were healthcare workers, which might limit the relationships of air pollutant DEDs and plasma NAb titers. However, as described in previous studies, our results emphasized that chronic environmental pollutant exposure inhibits the expression of the vaccine antibody in humans (Lin et al. 2017; Lin et al. 2016; Xu et al. 2015). In addition, an individual special residential address for each participant was not registered, but all participants were healthcare workers with the same place of work and live in Suining $\left(85.04 \mathrm{~km}^{2}\right.$ area). This ensured that the activity radius of all participants was less than $40 \mathrm{~km}$ from the nearest station, which is the threshold of monitoring station air pollutant data for assessing individual exposure (Bowe et al. 2017; Wang et al. 2020).

\section{Conclusion}

In summary, we conducted a cross-sectional study to estimate the relationship between air pollutant exposure and plasma $\mathrm{NAb}$ titers of an inactivated SARS-CoV-2 (Vero cell, CoronaVac, SINOV $\Lambda$ C, China) vaccination. The results indicated that the median plasma NAb titer is $12.81 \mathrm{AU} / \mathrm{mL}$, with $85.99 \%$ vaccine efficacy in healthcare workers against SARS$\mathrm{CoV}-2$. In addition, we observed increased incidence of chronic inflammatory status and decreased plasma NAb titers in the air pollutant exposure group. Moreover, elevated air pollutant DEDs were found to be associated with decreased plasma NAb titers. Collectively, our results support the hypothesis that long-term exposure to air pollutants may inhibit plasma NAb expression by inducing chronic inflammation. Therefore, to obtain herd immunity against SARS-CoV-2 infection and to stop the COVID-19 pandemic, local air pollution should be considered as a factor in future vaccination programs.

Supplementary Information The online version contains supplementary material available at https://doi.org/10.1007/s11356-021-16786-y.

Acknowledgements We acknowledge all the recruited healthcare workers for participating in this project. We also thank the LetPub (www.letpub.com) for its linguistic assistance during the preparation of this manuscript.

Author contribution Shaocheng Zhang designed the study, searched the literature, supervised data acquisition, revised the manuscript, and funded the study. Shu Chen and Guangjun Xiao worked for sampling, questionnaire collection, data analysis, and wrote the manuscript. Mingcai Zhao and $\mathrm{Jia} \mathrm{Li}$ contributed equally to the work for sampling collections and experiment implementation. Wenjuan Dong, Juan Hu, and Lianghua Liu assisted in sampling and questionnaire collection. Tianqi Yuan and Yong Li helped in the process of the experiment for techniques.

Funding This work was supported by the Doctoral Scientific Research Initiation Fund of Suining Central Hospital, China (SNCH210201).

Data availability All data generated or analyzed are included in this published article and supplement. 


\section{Declarations}

Ethical approval This study was approved by the Medical Research Ethics Committee of Suining Central Hospital, China (LLSNCH20210012).

Consent to participate and consent for publication All participants signed an informed consent, and all health data was handled anonymously in this study.

Competing interests The authors declare no competing interests.

\section{References}

Al Kaabi N, Zhang Y, Xia S, Yang Y, Al Qahtani MM, Abdulrazzaq N, Al Nusair M, Hassany M, Jawad JS, Abdalla J, Hussein SE, Al Mazrouei SK, Al Karam M, Li X, Yang X, Wang W, Lai B, Chen W, Huang $S$ et al (2021) Effect of 2 inactivated SARS-CoV-2 vaccines on symptomatic COVID-19 infection in adults: a randomized clinical trial. JAMA

Amanat F, Krammer F (2020) SARS-CoV-2 vaccines: status report. Immunity 52:583-589

Baden LR, El Sahly HM, Essink B, Kotloff K, Frey S, Novak R, Diemert D, Spector SA, Rouphael N, Creech CB, McGettigan J, Khetan S, Segall N, Solis J, Brosz A, Fierro C, Schwartz H, Neuzil K, Corey L et al (2021) Efficacy and safety of the mRNA-1273 SARS-CoV-2 vaccine. N Engl J Med 384:403-416

Barouki R, Kogevinas M, Audouze K, Belesova K, Bergman A, Birnbaum L, Boekhold S, Denys S, Desseille C, Drakvik E, Frumkin H, Garric J, Destoumieux-Garzon D, Haines A, Huss A, Jensen G, Karakitsios S, Klanova J, Koskela IM et al (2021) https:// www.heraresearcheu.eu, H.-C.-w.g.E.a. The COVID-19 pandemic and global environmental change: emerging research needs. Environ Int 146:106272

Bowe B, Xie Y, Li T, Yan Y, Xian H, Al-Aly Z (2017) Associations of ambient coarse particulate matter, nitrogen dioxide, and carbon monoxide with the risk of kidney disease: a cohort study. Lancet Planet Health 1:e267-e276

Calderon-Garciduenas L, Macias-Parra M, Hoffmann HJ, ValenciaSalazar G, Henriquez-Roldan C, Osnaya N, Monte OC, BarraganMejia G, Villarreal-Calderon R, Romero L, Granada-Macias M, Torres-Jardon R, Medina-Cortina H, Maronpot RR (2009) Immunotoxicity and environment: immunodysregulation and systemic inflammation in children. Toxicol Pathol 37:161-169

Chabot-Richards DS, George TI (2014) Leukocytosis. Int J Lab Hematol $36: 279-288$

Chen X, Chen Z, Azman AS, Deng X, Sun R, Zhao Z, Zheng N, Chen X, Lu W, Zhuang T, Yang J, Viboud C, Ajelli M, Leung DT, Yu H (2021) Serological evidence of human infection with SARS-CoV-2: a systematic review and meta-analysis. Lancet Glob Health 9:e598e609

Cong X, Xu X, Xu L, Li M, Xu C, Qin Q, Huo X (2018) Elevated biomarkers of sympatho-adrenomedullary activity linked to ewaste air pollutant exposure in preschool children. Environ Int 115:117-126

Copat C, Cristaldi A, Fiore M, Grasso A, Zuccarello P, Signorelli SS, Conti GO, Ferrante M (2020) The role of air pollution (PM and NO2) in COVID-19 spread and lethality: a systematic review. Environ Res 191:110129

Dabass A, Talbott EO, Rager JR, Marsh GM, Venkat A, Holguin F, Sharma RK (2018) Systemic inflammatory markers associated with cardiovascular disease and acute and chronic exposure to fine particulate matter air pollution (PM2.5) among US NHANES adults with metabolic syndrome. Environ Res 161:485-491

Dargahi A, Jeddi F, Ghobadi H, Vosoughi M, Karami C, Sarailoo M, Hadisi A, Mokhtari SA, Haghighi SB, Sadeghi H, Alighadri M (2021a) Evaluation of masks' internal and external surfaces used by health care workers and patients in coronavirus-2 (SARS-CoV2) wards. Environ Res 196:110948

Dargahi A, Jeddi F, Vosoughi M, Karami C, Hadisi A, Mokhtari SA, Ghobadi H, Alighadri M, Haghighi SB, Sadeghi H (2021b) Investigation of SARS-CoV-2 virus in environmental surface. Environ Res 195:110765

Fareed Z, Iqbal N, Shahzad F, Shah SGM, Zulfiqar B, Shahzad K, Hashmi SH, Shahzad U (2020) Co-variance nexus between COVID-19 mortality, humidity, and air quality index in Wuhan, China: new insights from partial and multiple wavelet coherence. Air Qual Atmos Health 8:1-10

He Z, Ren L, Yang J, Guo L, Feng L, Ma C, Wang X, Leng Z, Tong X, Zhou W, Wang G, Zhang T, Guo Y, Wu C, Wang Q, Liu M, Wang C, Jia M, Hu X et al (2021) Seroprevalence and humoral immune durability of anti-SARS-CoV-2 antibodies in Wuhan, China: a longitudinal, population-level, cross-sectional study. Lancet 397:10751084

Hodgson SH, Mansatta K, Mallett G, Harris V, Emary KRW, Pollard AJ (2021) What defines an efficacious COVID-19 vaccine? A review of the challenges assessing the clinical efficacy of vaccines against SARS-CoV-2. Lancet Infect Dis 21:e26-e35

Huang Y, Wang L, Zhang S, Zhang M, Wang J, Cheng X, Li T, He M, Ni S (2020) Source apportionment and health risk assessment of air pollution particles in eastern district of Chengdu. Environ Geochem Health 42:2251-2263

Karami C, Dargahi A, Vosoughi M, Normohammadi A, Jeddi F, Asghariazar V, Mokhtari SA, Sedigh A, Zandian H, Alighadri M (2021a) SARS-CoV-2 in municipal wastewater treatment plant, collection network, and hospital wastewater. Environ Sci Pollut Res Int 15:1-9

Karami C, Normohammadi A, Dargahi A, Vosoughi M, Zandian H, Jeddi F, Mokhtari SA, Moradi-Asl E (2021b) Investigation of SARSCoV-2 virus on nozzle surfaces of fuel supply stations in North West of Iran. Sci Total Environ 780:146641

Konstantinoudis G, Padellini T, Bennett J, Davies B, Ezzati M, Blangiardo M (2021) Long-term exposure to air-pollution and COVID-19 mortality in England: a hierarchical spatial analysis. Environ Int 146:106316

Lin X, Xu X, Zeng X, Xu L, Zeng Z, Huo X (2017) Decreased vaccine antibody titers following exposure to multiple metals and metalloids in e-waste-exposed preschool children. Environ Pollut 220:354-363

Lin Y, Xu X, Dai Y, Zhang Y, Li W, Huo X (2016) Considerable decrease of antibody titers against measles, mumps, and rubella in preschool children from an e-waste recycling area. Sci Total Environ 573:760-766

Logunov DY, Dolzhikova IV, Shcheblyakov DV, Tukhvatulin AI, Zubkova OV, Dzharullaeva AS, Kovyrshina AV, Lubenets NL, Grousova DM, Erokhova AS, Botikov AG, Izhaeva FM, Popova O, Ozharovskaya TA, Esmagambetov IB, Favorskaya IA, Zrelkin DI, Voronina DV, Shcherbinin DN et al (2021) Safety and efficacy of an rAd26 and rAd5 vector-based heterologous prime-boost COVID-19 vaccine: an interim analysis of a randomised controlled phase 3 trial in Russia. Lancet 397:671-681

Lopez-Feldman A, Heres D, Marquez-Padilla F (2021) Air pollution exposure and COVID-19: a look at mortality in Mexico City using individual-level data. Sci Total Environ 756:143929

Lu X, Xu X, Zhang Y, Zhang Y, Wang C, Huo X (2018) Elevated inflammatory Lp-PLA2 and IL-6 link e-waste $\mathrm{Pb}$ toxicity to cardiovascular risk factors in preschool children. Environ Pollut 234:601609 
Paital B (2020) Nurture to nature via COVID-19, a self-regenerating environmental strategy of environment in global context. Sci Total Environ 729:139088

Paital B, Agrawal PK (2020) Air pollution by $\mathrm{NO}_{2}$ and $\mathrm{PM}_{2.5}$ explains COVID-19 infection severity by overexpression of angiotensinconverting enzyme 2 in respiratory cells: a review. Environ Chem Lett 18:1-18

Paital B, Das K (2021) Spike in pollution to ignite the bursting of COVID-19 second wave is more dangerous than spike of SARCoV-2 under environmental ignorance in long term: a review. Environ Sci Pollut Res Int 14:1-17

Polack FP, Thomas SJ, Kitchin N, Absalon J, Gurtman A, Lockhart S, Perez JL, Perez Marc G, Moreira ED, Zerbini C, Bailey R, Swanson KA, Roychoudhury S, Koury K, Li P, Kalina WV, Cooper D, Frenck RW Jr, Hammitt LL et al (2020) Safety and efficacy of the BNT162b2 mRNA COVID-19 vaccine. N Engl J Med 383:26032615

Qiao B, Chen Y, Tian M, Wang H, Yang F, Shi G, Zhang L, Peng C, Luo Q, Ding S (2019) Characterization of water soluble inorganic ions and their evolution processes during PM2.5 pollution episodes in a small city in southwest China. Sci Total Environ 650:2605-2613

Rich DQ, Kipen HM, Huang W, Wang G, Wang Y, Zhu P, OhmanStrickland P, Hu M, Philipp C, Diehl SR, Lu SE, Tong J, Gong J, Thomas D, Zhu T, Zhang JJ (2012) Association between changes in air pollution levels during the Beijing Olympics and biomarkers of inflammation and thrombosis in healthy young adults. JAMA 307: 2068-2078

Sadoff J, Gray G, Vandebosch A, Cardenas V, Shukarev G, Grinsztejn B, Goepfert PA, Truyers C, Fennema H, Spiessens B, Offergeld K, Scheper G, Taylor KL, Robb ML, Treanor J, Barouch DH, Stoddard J, Ryser MF, Marovich MA et al (2021) Safety and efficacy of single-dose Ad26.COV2.S vaccine against COVID-19. N Engl J Med 384:2187-2201

Sarailoo M, Matin S, Vosoughi M, Dargahi A, Gholizadeh H, Damavandi MR, Abbasi-Ghahramanloo A, Kamran A (2021) Investigating the relationship between occupation and SARSCoV2. Work 68(1):27-32

Sarwar S, Shahzad K, Fareed Z, Shahzad U (2021) A study on the effects of meteorological and climatic factors on the COVID-19 spread in Canada during 2020. J Environ Health Sci Eng 16:1-9

Shahzad K, Shahzad U, Iqbal N, Shahzad F, Fareed Z (2020) Effects of climatological parameters on the outbreak spread of COVID-19 in highly affected regions of Spain. Environ Sci Pollut Res Int 27(31): 39657-39666

Shahzad K, Farooq TH, Dogan B, Hu LZ, Shahzad U (2021) Does environmental quality and weather induce COVID-19: case study of Istanbul, Turkey. Environ Forensic:1-12. https://doi.org/10.1080/ 15275922.2021.1940380

Shakoor A, Chen X, Farooq TH, Shahzad U, Ashraf F, Rehman A, Sahar NE, Yan W (2020) Fluctuations in environmental pollutants and air quality during the lockdown in the USA and China: two sides of COVID-19 pandemic. Air Qual Atmos Health 9:1-8

So J, Wu D, Lichtenstein AH, Tai AK, Matthan NR, Maddipati KR, Lamon-Fava S (2021) EPA and DHA differentially modulate monocyte inflammatory response in subjects with chronic inflammation in part via plasma specialized pro-resolving lipid mediators: a randomized, double-blind, crossover study. Atherosclerosis 316:90-98

Srivastava A (2021) COVID-19 and air pollution and meteorology-an intricate relationship: a review. Chemosphere 263:128297

Tanriover, M.D.; Doğanay, H.L.; Akova, M.; Güner, H.R.; Azap, A.; Akhan S; Köse Ș; Erdinç F; Akalın, E.H.; Tabak Ö, F.; Pullukçu, H.; Batum, Ö.; Șimșek Yavuz, S.; Turhan, Ö.; Yıldırmak, M.T.; Köksal, İ.; Taşova, Y.; Korten, V.; Yılmaz, G.; Çelen, M.K.; Altın, S.; Çelik, İ.; Bayındır, Y.; Karaoğlan, İ.; Yılmaz, A.; Özkul, A.; Gür, H.; Unal, S. Efficacy and safety of an inactivated wholevirion SARS-CoV-2 vaccine (CoronaVac): interim results of a double-blind, randomised, placebo-controlled, phase 3 trial in Turkey. Lancet (London, England) 2021; https://doi.org/10.1016/ S0140-6736(21)01429-X

Travaglio M, Yu Y, Popovic R, Selley L, Leal NS, Martins LM (2021) Links between air pollution and COVID-19 in England. Environ Pollut 268:115859

Verheyen VJ, Remy S, Bijnens EM, Colles A, Govarts E, Martin LR, Koppen G, Bruckers L, Nielsen F, Vos S, Morrens B, Coertjens D, De Decker A, Franken C, Den Hond E, Nelen V, Covaci A, Loots I, De Henauw $S$ et al (2021) Long-term residential exposure to air pollution is associated with hair cortisol concentration and differential leucocyte count in Flemish adolescent boys. Environ Res 201: 111595

Vosoughi M, Karami C, Dargahi A, Jeddi F, Jalali KM, Hadisi A, Haghighi SB, Dogahe HP, Noorimotlagh Z, Mirzaee SA (2021) Investigation of SARS-CoV-2 in hospital indoor air of COVID-19 patients' ward with impinger method. Environ Sci Pollut Res Int 6: $1-9$

Voysey M, Clemens SAC, Madhi SA, Weckx LY, Folegatti PM, Aley PK et al (2021) Safety and efficacy of the ChAdOx1 nCoV-19 vaccine (AZD1222) against SARS-CoV-2: an interim analysis of four randomised controlled trials in Brazil, South Africa, and the UK. Lancet (London, England) 397:99-111

Wang H, Tian M, Chen Y, Shi G, Liu Y, Yang F, Zhang L, Deng L, Yu J, Peng C, Cao X (2018) Seasonal characteristics, formation mechanisms and source origins of PM\&lt;sub\&gt;2.5\&lt;/sub\&gt; in two megacities in Sichuan Basin, China. Atmos Chem Phys 18:865-881

Wang HH, Zhang SC, Wang J, Chen X, Yin H, Huang DY (2020) Combined toxicity of outdoor air pollution on kidney function among adult women in Mianyang City, southwest China. Chemosphere 238:124603

WHO. Coronavirus (COVID-19) Dashboard. https://covid19.who.int (accessed September 16, 2021).

Wild CP, Kleinjans J (2003) Children and increased susceptibility to environmental carcinogens: evidence or empathy? Cancer epidemiology, biomarkers \& prevention : a publication of the American Association for Cancer Research, cosponsored by the American Society of Preventive Oncology 12:1389-1394

Woodby B, Arnold MM, Valacchi G (2021) SARS-CoV-2 infection, COVID-19 pathogenesis, and exposure to air pollution: what is the connection? Ann N Y Acad Sci 1486(1):15-38

Wu X, Nethery RC, Sabath BM, Braun D, Dominici F (2020) Exposure to air pollution and COVID-19 mortality in the United States: a nationwide cross-sectional study. medRxiv. https://doi.org/10. 1101/2020.04.05.20054502

Xu X, Chen X, Zhang J, Guo P, Fu T, Dai Y, Lin SL, Huo X (2015) Decreased blood hepatitis B surface antibody levels linked to ewaste lead exposure in preschool children. J Hazard Mater 298: $122-128$

Xu X, Jiang SY, Wang TY, Bai Y, Zhong M, Wang A, Lippmann M, Chen LC, Rajagopalan S, Sun Q (2013) Inflammatory response to fine particulate air pollution exposure: neutrophil versus monocyte. PLoS One 8:e71414

Zhang H, Wei K, Zhang M, Liu R, Chen Y (2014) Assessing the mechanism of DNA damage induced by lead through direct and indirect interactions. J Photochem Photobiol B 136:46-53

Zhang N, Jack Chan PT, Jia W, Dung CH, Zhao P, Lei H, Su B, Xue P, Zhang W, Xie J, Li Y (2021a) Analysis of efficacy of intervention strategies for COVID-19 transmission: a case study of Hong Kong. Environ Int 156:106723

Zhang S, Chen X, Wang J, Dai C, Gou Y, Wang H (2021b) Particulate air pollution and respiratory Haemophilus influenzae infection in Mianyang, southwest China. Environ Sci Pollut Res Int 28:3315833164. https://doi.org/10.1007/s11356-021-13103-5 
Zhang S, Huo X, Zhang Y, Huang Y, Zheng X, Xu X (2019a) Ambient fine particulate matter inhibits innate airway antimicrobial activity in preschool children in e-waste areas. Environ Int 123:535-542

Zhang S, Huo X, Zhang Y, Lu X, Xu C, Xu X (2019b) The association of PM2.5 with airway innate antimicrobial activities of salivary agglutinin and surfactant protein D. Chemosphere 226:915-923

Zhang X, Tang M, Guo F, Wei F, Yu Z, Gao K, Jin M, Wang J, Chen K (2021c) Associations between air pollution and COVID-19 epidemic during quarantine period in China. Environ Pollut 268:115897

Zheng X, Xu X, Yekeen TA, Zhang Y, Chen A, Kim SS, Kim N, Dietrich KND, Ho S-M, Lee S-A, Reponen T, Huo X (2016) Ambient air heavy metals in PM2.5 and potential human health risk assessment in an informal electronic-waste recycling site of China. Aerosol Air Qual Res 16:388-397

Zhu Y, Xie J, Huang F, Cao L (2020) Association between short-term exposure to air pollution and COVID-19 infection: evidence from China. Sci Total Environ 727:138704

Publisher's note Springer Nature remains neutral with regard to jurisdictional claims in published maps and institutional affiliations. 